\title{
Immortalization of Human Endothelial Cells by Origin-defective Simian Virus 40 DNA
}

\author{
Shinji ImJma, ${ }^{\dagger}$ Mitsuyoshi Ishma, ${ }^{*}$ Sadayo NaKajima-Iijima, ${ }^{*}$ \\ Tadashi Hishida, ${ }^{*}$ Hideki Watanabe \\ and Takeshi KOBAYASHI \\ Department of Biotechnology, Faculty of Engineering, Nagoya University, \\ Furo-cho, Chikusa-ku, Nagoya 464-01, Japan \\ * Bioscience Laboratory, Research Center, Mitsubishi Kasei Co., \\ Kamoshida-cho, Midori-ku, Yokohama 227, Japan \\ Received May 20, 1991
}

\begin{abstract}
Human endothelial cells isolated from an umbilical cord vein were transfected with origin-defective simian virus 40 (SV 40) DNA. Among several of the SV 40 transfected clones isolated, cell lines SV-2 and SV-3 showed a normal endothelial cell morphology and extended life span, and could survive almost 100 generations. Just before crisis, the morphology of SV-3 changed. SV-3T cell line was isolated from this SV-3 culture, which acquired an almost infinite life span, rapid growth rate and the ability to grow in soft agar. At the same time, the SV-3T cell line lost the factor VIII-related antigen and normal endothelial cell morphology, and showed an abnormal chromosome number. Further characterization showed the ability of SV-2 and SV-3T to produce increasing amounts of tissue plasminogen activator and a similar level of a plasminogen activator inhibitor compared with normal human endothelial cells. These results indicate that the SV-3T cell line was transformed and acquired an infinite life span while still retaining a part of the differentiated endothelial cell characteristics.
\end{abstract}

Endothelial cells have important functions in fibrinolysis and angiogenesis to attain homeostasis in animals. ${ }^{1,2)}$ In the last several decades, in vitro culture of human endothelial cells has been reported, ${ }^{3)}$ and endothelial cell growth factors were identified. ${ }^{4)}$ Furthermore, a serum-free medium has been developed for these cells. ${ }^{5}$ ) Under the certain conditions like those with an extracellular matrix such as collagen and in the presence of the basicfibroblast growth factor (basic-FGF), a blood vessel-like tube formation has been shown by in vitro culture of bovine endothelial cells. ${ }^{6}$

Despite these findings, the life span of primary endothelial cells is limited, and this is still one of the major problems for basic research into the functions of endothelial cells and the development of new therapeutical agents for blood vessel-related diseases. One of the factors limiting mammalian cell culture technology is the relative scarcity of established human cell lines which retain differentiated cell characteristics and can be used for the production of biologically active substances.

It has been reported that in vitro transformation by oncogenes ${ }^{7)}$ and the development of cell lines with an infinite life $\operatorname{span}^{8)}$ are relatively difficult with human primary culture, while several viruses displayed cell line establishment activity. ${ }^{9)}$ Among these viruses, simian virus 40 (SV40) was often used for developing human cell lines with an infinite or prolonged life span. A $94 \mathrm{~K}$ early region protein (large $\mathrm{T}$ antigen), which has multiple functions of replication, transcription and binding to socalled tumor supressor protein p53, etc. ${ }^{10,11)}$ is known to be important for the immortalization of cells. ${ }^{12)}$ Several papers have reported the establishment of cell lines by infecting the entire or early region of the virus genome to

\footnotetext{
$\dagger$ To whom correspondence should be addressed.
} 
human fibroblast ${ }^{7)}$ and kidney cells. ${ }^{13)}$

In this study, a human endothelial cell primary culture was transfected with cloned replication-defective SV40 virus DNA, ${ }^{14)}$ and cell lines with an infinite or prolonged life span were obtained. These cell lines showed some of the characteristics of normal endothelial cells.

\section{Materials and Methods}

Isolation of human endothelial cells from an umbilical cord vein. Human endothelial cells were isolated from an umbilical cord vein basically as reported by Jaffe, ${ }^{15)}$ but with $0.1 \%$ trypsin being perfused instead of collagenase. The isolated cells were cultured in 199 medium containing $20 \%$ fetal calf serum, $0.3 \mathrm{mg} / \mathrm{ml}$ of endothelial cell growth supplement (Collaborative Research Inc., Bedford, MA) and $90 \mu \mathrm{g} / \mathrm{ml}$ of heparin (Sigma, St. Louis, MO). Culture dishes were coated with type 1 collagen (Collaborative Research Inc.). After 2 cycle passages, the cells were used to transfect DNA and for other analyses.

SV40 DNA and transfection. Cloned origin-defective SV40 DNA ${ }^{14)}$ was obtained from Dr. Y. Gluzman through Professor N. Yamaguchi of The University of Tokyo. Plasmid DNA was purified by the standard procedure of cleared lysate and cesium chloride ethidium bromide equilibrium centrifugation. ${ }^{16}$ ) The plasmid DNA containing origin-defective SV40 genomic DNA was cut by a restriction enzyme $(B a m \mathrm{HI})$ and ligated to form SV40 circular DNA. About $4 \mu \mathrm{g}$ of the recombinant DNA was added to $1.2 \mathrm{ml}$ of a $75 \mu \mathrm{g} / \mathrm{ml} \mathrm{DEAE-dextran}$ solution, and the mixture stood for $20 \mathrm{~min}$ at room temperature. Human endothelial cells at 3 passages in $60 \mathrm{~mm}$ dishes (semi-confluent) were washed 3 times with serum-free 199 medium, and the DNA-DEAE dextran mixture was then added. After standing for $5 \mathrm{hr}$ at $37^{\circ} \mathrm{C}$ in the presence of $5 \% \mathrm{CO}_{2}$, the DNA-DEAE dextran solution was removed. Then, $10 \%$ dimethylsulfoxide in phosphate-buffered saline $\left(\mathrm{Na}_{2} \mathrm{HPO}_{4} \cdot 12 \mathrm{H}_{2} \mathrm{O}, 2.9 \mathrm{~g} /\right.$ liter; $\mathrm{KH}_{2} \mathrm{PO}_{4}, 0.2 \mathrm{~g} /$ liter; $\mathrm{NaCl}, 8 \mathrm{~g}$ /liter; $\mathrm{KCl}, 0.2 \mathrm{~g}$ /liter; $\mathrm{pH}$ 7.4) was added, and the dishes were stood for $2 \mathrm{~min}$. The cells were washed twice with the phosphate-buffered saline and then cultured in the 199 medium containing $10 \%$ fetal calf serum, $0.3 \mathrm{mg} / \mathrm{ml}$ of endothelial cell growth supplement and $90 \mu \mathrm{g} / \mathrm{ml}$ of heparin. After 6 cycle passages, the medium was changed to 199 medium containing $10 \%$ fetal calf serum without the endothelial cell growth supplement and heparin. After 5 cycle passages in the growth supplement-free medium, the colonies were isolated.

$D N A$ isolation. High molecular weight DNA was isolated by a standard procedure, ${ }^{16)}$ digested with restriction enzyme $P v u \mathrm{II}$ and fractionated by agarose gel electrophoresis. SV 40 sequences were detected by Southern blot analyses, ${ }^{16}$ ) using cloned entire SV40 sequences as a probe. For chromosome analyses, metaphase cells were obtained by a colchicine treatment, and the chromosome pattern was analyzed. ${ }^{17)}$

Immunological methods. The production of factor VIII-related antigen was detected with acetone-fixed cells by an immunocytochemical analysis, using fluorescein isothiocyanate (FITC)-labeled anti-factor VIII antibody (Serotec Co., Oxford, England). Production of the large $\mathrm{T}$ antigen was also detected with formalin-fixed and methanol, acetone-permealized cell samples, using mouse anti-large $\mathrm{T}$ antigen antibody (Oncogene Science Inc., Manhasset, NY) and FITC-labeled rabbit anti-mouse IgG (Kappel, Organon Teknika Co., West Chester, PA).

Tissue plasminogen activator (tPA) and plasminogen activator inhibitor-1 (PAI-1) were determined by an enzyme-linked immunosorbent assay (ELISA). For the measurements, $10^{5}$ cells were inoculated in 24-well dishes (Farcon, Nippon Becton Dickinson Co., Tokyo) and cultured with RPMI1640 medium (Gibco Oriental Co., Tokyo) containing $10 \%$ fetal calf serum. After a $16 \mathrm{~h}$ culture, the medium was changed ( $1 \mathrm{ml}$ ) and the cultivation was continued for another $48 \mathrm{~h}$. The culture medium was then taken up and the amounts of tPA and PAI-1 were determined. For the detection of tPA, rabbit anti-human tPA IgG and biotinylated rabbit anti-human tPA IgGF $\left(\mathrm{ab}^{\prime}\right)_{2}$ were used as the primary and secondary antibodies. For PAI-1, anti-human PAI-I monoclonal antibody and biotinylated rabbit anti-human PAI-I IgGF $\left(a b^{\prime}\right)_{2}$ were used.

Other methods. For the measurement of DNA synthesis, ${ }^{3} \mathrm{H}$-thymidine $(0.4 \mu \mathrm{Ci})$ was added to $200 \mu \mathrm{l}$ of RPMI 1640 medium containing $10 \%$ fetal celf serum, and cells were cultured. The cells were removed at suitable time intervals, and the incorporated ${ }^{3} \mathrm{H}$-thymidine was measured with a liquid scintillation counter. To study the effects of growth factors, $0.5 \mu \mathrm{g} / \mathrm{ml}$ of tumor growth factor $\beta$ (TGF- $\beta$ ) or $10 \mathrm{ng} / \mathrm{ml}$ of basic-FGF was included in the medium, and the incorporation of ${ }^{3} \mathrm{H}$-thymidine was measured.

\section{Results}

Isolated human endothelial cells were passaged three times and transfected with cloned origin-defective SV40 DNA by the DEAEdextran method. Since human cells are semipermissive to SV40 infection and are usually killed by this virus in vitro, ${ }^{14)}$ the origin-defective virus DNA was used in this study. After 6 passages $(1: 4)$ in the medium containing heparin and the endothelial cell growth sup- 


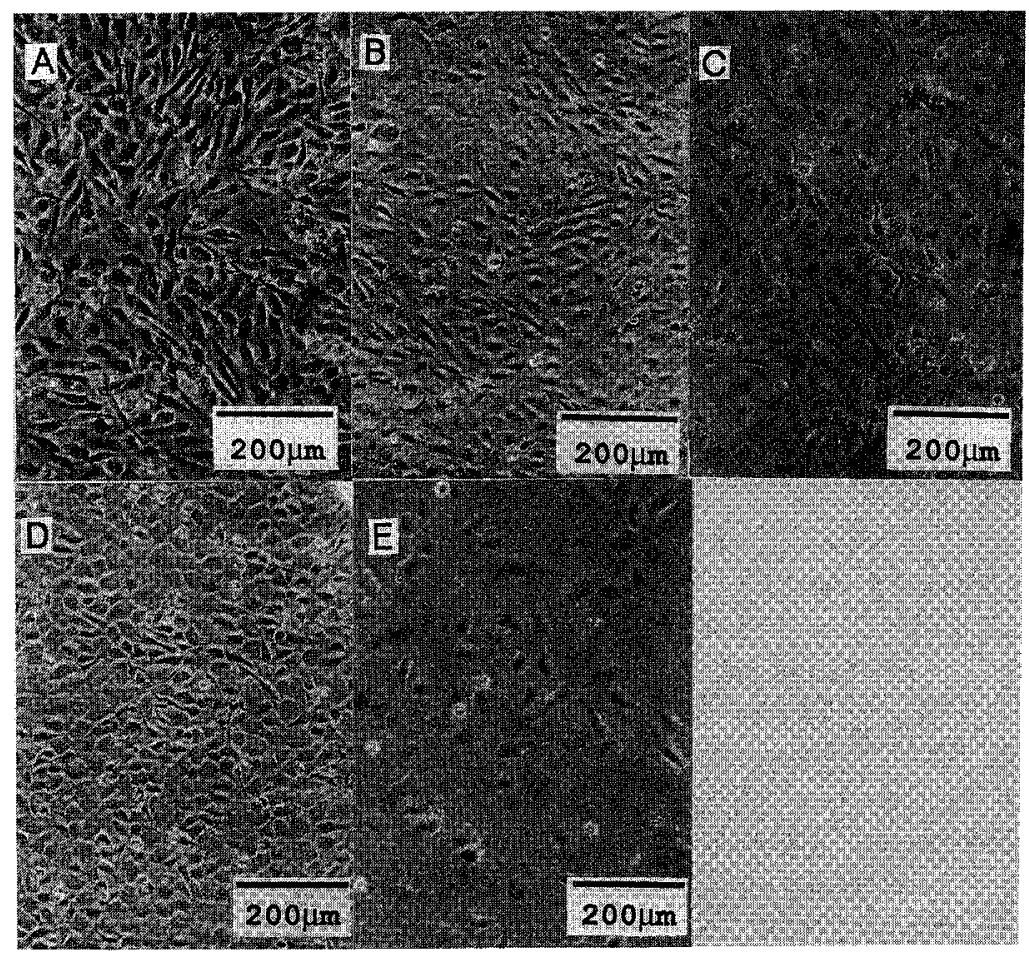

Fig. 1. Photographs of SV40 Transfected Human Endothelial Cell Clones.

A, normal endothelial cells; B, SV-2; C, SV-3 before crisis; D, transformed SV-3 in a saturated culture; E, transformed $\mathrm{SV}-3$ in a sparse culture.

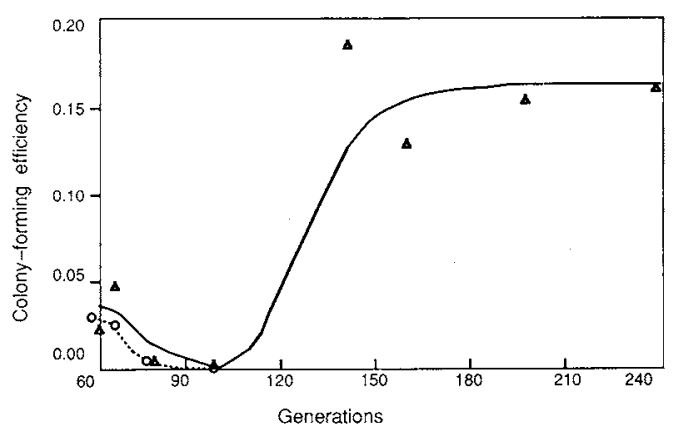

Fig. 2. Changes in the Colony-forming Efficiency after Passages.

$\bigcirc \cdots O, \mathrm{SV}-2 ; \triangle-\triangle, \mathrm{SV}-3$.

plement, the transfected cells were further cultured in the absence of the supplements. The cells were then plated by a series of dilutions to form colonies. Twenty five colonies were picked up and propagated, these being designated as SV-1 to SV-25. Out of them, SV-2 and SV-3 showed an extended life span

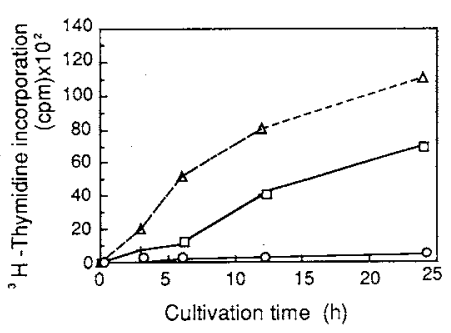

Fig. 3. DNA Synthesis of Normal Endothelial Cells (O), SV-2 $(\square)$ and SV-3T $(\triangle)$ without the Endothelial Cell Growth Factor.

and typical endothelial cell morphology (Fig. 1A-C), while the other 23 colonies succumbed to crisis and cell death after shorter passages.

Cell lines SV-2 and SV-3 were subcultured (1:5 dilution when they were confluent) to determine their life span and colony-forming ability. As shown in Fig. 2, both cell lines showed a decreased colony forming ability through passages, SV-2 undergoing senescence and dying after around 100 generations as 
calculated from the cell isolation from umbilical cord vein. The colony-forming ability of SV-3 increased suddenly after 100 generations. At the same time, the cell morphology in a confluent culture changed and the cells assumed an irregular shape, suggesting that they had been morphologically transformed (Fig. 1D). The morphology of SV-3 in a sparse culture was not so different from normal endothelial cells (Fig. 1E). From the transformed SV-3 cells after passages of more than 100 generations, a typical single colony was isolated and designated as SV-3T. The DNA synthesis rate of SV-3T was higher compared with SV-2 and normal endothelial cells as shown in Fig. 3, when judged by the incorporation of ${ }^{3} \mathrm{H}$-thymidine. The cell density in a confluent culture seemed to increase, which suggests that contact inhibition might have partly disappeared. Only SV-3T could form colonies in soft agar, while SV-2 and untransformed SV-3 could not. All these observations suggest that the SV-3T cells had been transformed. However, SV-3T still could not grow in a suspension culture nor in a serum-free medium such as DF-ITES ${ }^{18)}$ or GIT (Nihon Pharmaceutical Co., Osaka) medium.

Endothelial cell-specific characteristics such as the production of factor VIII-related antigen, plasminogen activator and a plasminogen activator inhibitor were studied. Figure 4 shows the results of an immunocytochemical staining of factor VIII-related antigen. Cell line SV-2 expressed the antigen, but to a lower degree than normal endothelial cells. On the other hand, SV-3T did not produce the antigen at all. As measured by ELISA, cell lines SV-2 and SV-3T produced more tPA than primary endothelial cells (Table I). The production of PAI-1 was also checked with these cell lines, SV-2 and SV-3T cells producing almost the

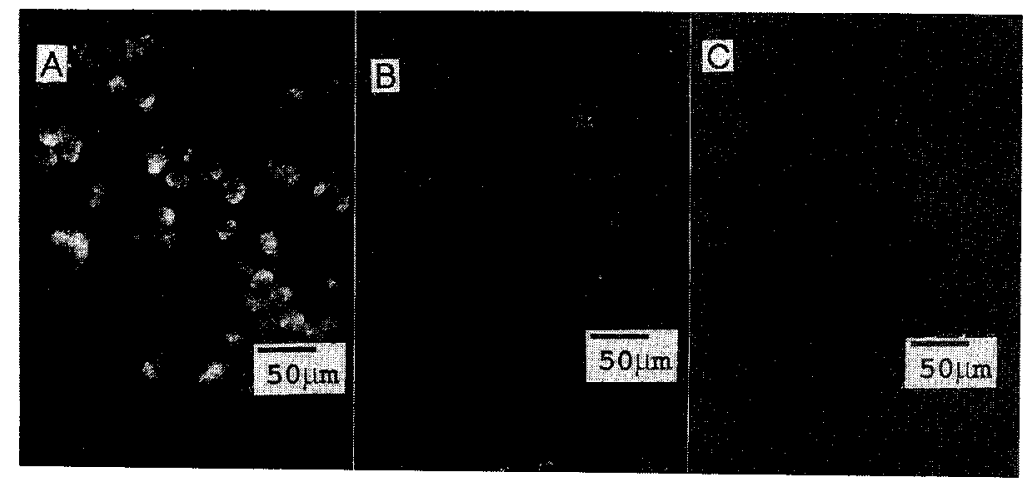

Fig. 4. Immunocytochemical Detection of the Factor VIII-related Antigen in Normal Endothelial Cells (A), SV-2 (B) and SV-3 (C).

Table I. Characteristics of SV40-transfected Human Endothelial Cell Lines SV-2 and SV-3T

\begin{tabular}{lccccc}
\hline & $\begin{array}{c}\text { PPA }^{a} \\
\mathrm{ng} / 48 \mathrm{~h}\end{array}$ & $\begin{array}{c}\mathrm{PAI}^{a} \\
\mu \mathrm{g} / 48 \mathrm{~h}\end{array}$ & $\begin{array}{c}\text { Effects on DNA synthesis by } \\
\text { basic-FGF }\end{array}$ & $\begin{array}{c}\text { Factor VIII-related } \\
\text { antigen }\end{array}$ \\
\hline SV-2 & 6 & 0.6 & n.d. $^{d}$ & n.d. $^{d}$ & + \\
SV-3T & 2 & 0.9 & \pm & \pm & - \\
Normal endo- & 1 & 0.9 & $+^{b}$ & & + \\
thelial cells & & & & & \\
\hline
\end{tabular}

a Per $1.2 \times 10^{5}$ cells

${ }^{b}$ Incorporation of ${ }^{3} \mathrm{H}$-thymidine was increased 1.4-fold compared to that in the growth factor-free medium.

c Incorporation of ${ }^{3} \mathrm{H}$-thymidine was decreased 0.75 -fold compared to that in the growth factor-free medium.

¿ Not determined. 
same level of PAI-1 compared with normal endothelial cells as shown in Table I.

It is well known that TGF- $\beta$ represses the growth of normal endothelial cells ${ }^{19}$ ) and that basic-FGF is one of the most potent endothelial cell growth factors. ${ }^{20}$ As shown in Table I, normal endothelial cells responded to

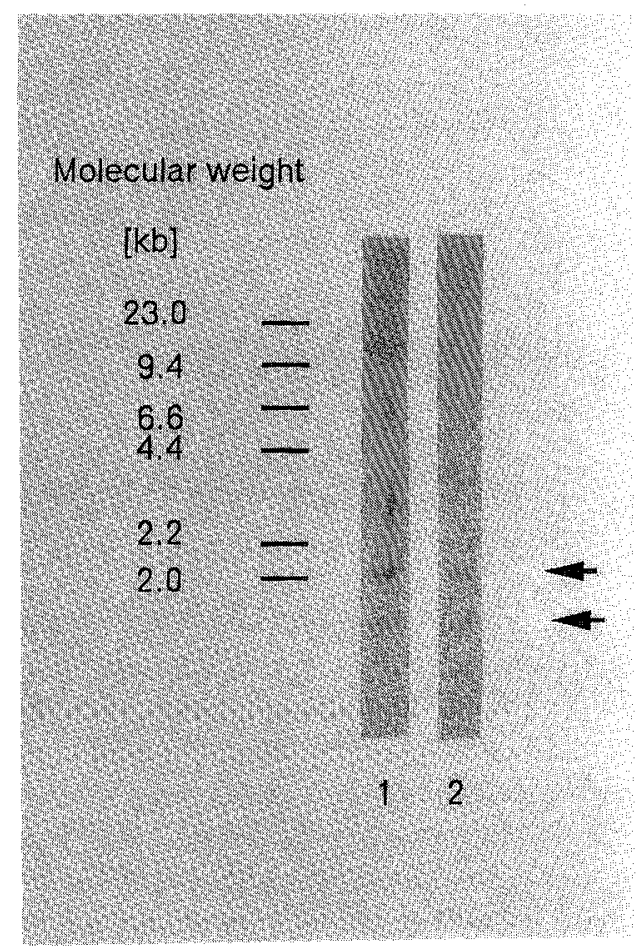

Fig. 5. Detection of the SV40 DNA Sequence in SV-2 (Lane 1) and SV-3T (lane 2).

Arrows show the positions of expected $P v u I$ fragments of the SV40 genome. these growth factors as reported: cell cycle inhibition by TGF- $\beta$ and stimulation by basicFGF in terms of DNA synthesis. However, these growth factors did not affect SV-3T cells.

To make sure that the infinite or prolonged life span shown by SV-3T or SV-2 was, at least partly, due to the SV40 large T antigen, we first checked the existence of SV40 genomic DNA in the cells. Figure 5 shows the results of Southern blot analyses of total cellular DNA from SV-2 and SV-3T, using entire SV40 genome as a probe. With both SV-2 and SV-3T cells, the expected 2007 and $1446 \mathrm{bp}$ $P v u I I$ fragments corresponding to the early and late regions of SV40 genome, respectively, were detected.

Figure 6 shows the fluorescence micrographs of the SV-2 and SV-3T cells stained by anti-large $T$ antibody. Both cell lines expressed the SV40 large T antigen. From these results, it was confirmed that both cell lines contained the SV40 sequences, and that the large T antigen was also expressed in both cell lines.

In several transformed cell lines, especially SV40 transformed cells, chromosome abnormality has been detected. ${ }^{7)}$ Therefore, we checked the chromosome number of the SV-2 and SV-3 cells at the metaphase (Fig. 7). SV-2 showed a chromosome range of $38-43$ at 60 generations and of 37-41 just before crisis. SV-3 showed a chromosome range of 38-43 at 96 generations but of 65-76 at 222 generations. Especially with SV-3 at 222 generations,

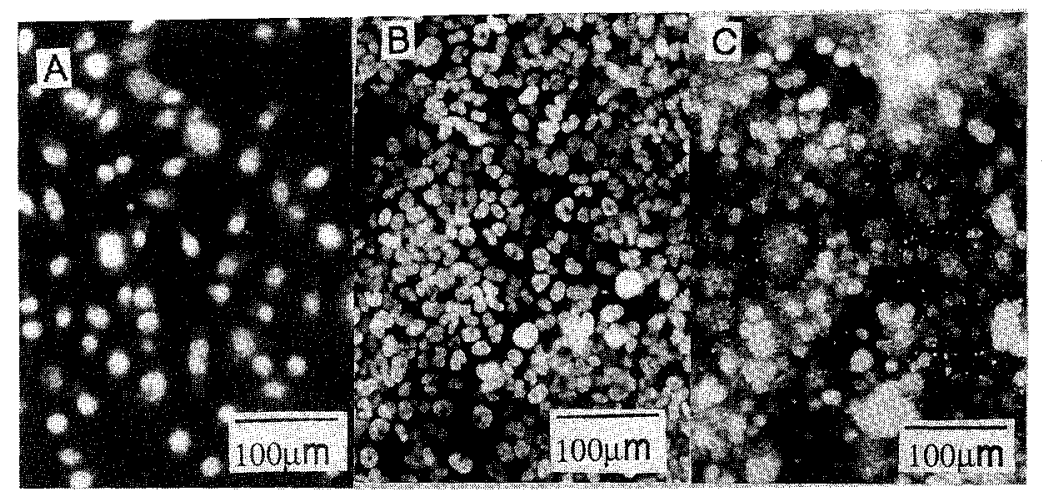

Fig. 6. Detection of the SV40 T-antigen by Immunocytochemical Staining of SV-2 (A), SV-3T (B) and COS Cells as the Control $(\mathrm{C})$. 

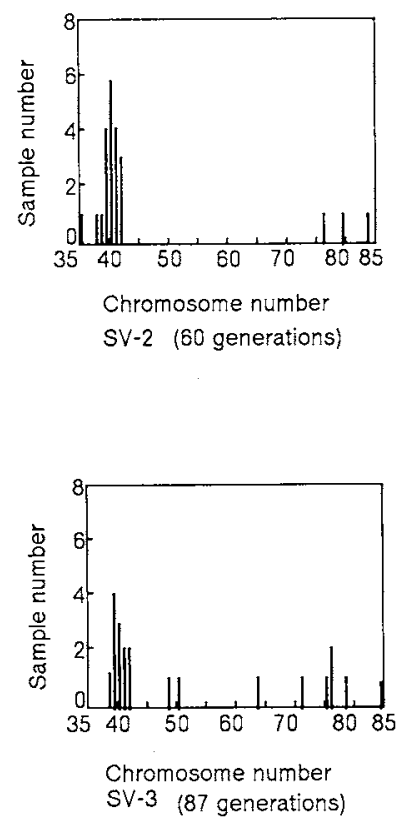
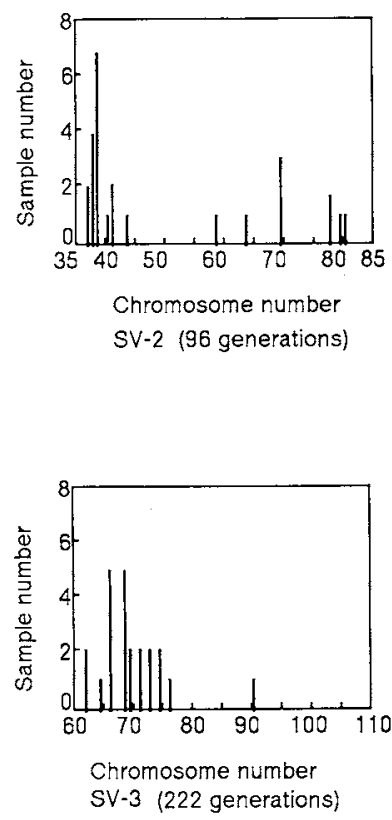

Fig. 7. Changes in the Chromosome Number of SV-2 and SV-3 Cells after Passages.

multiple rearrangements were detected, and the identification of each chromosome was very difficult by the G-banding method.

\section{Discussion}

Under optimal conditions, the life span of normal endothelial cells has been reported to be prolonged up to 80 generations. $^{21)}$ However, under our culture conditions, a normal primary culture of human endothelial cells could be passaged $4-5$ times by a $1: 4$ dilution, which means that the life span of the normal cells was within 20 generations. Therefore, cell lines SV-2 and SV-3 that could survive to 100 generations acquired a longer life span than primary endothelial cells. This extended life span and lower requirement for the growth factor seems to have been caused by the large $T$ antigen.

Among the SV40-DNA transfected human endothelial cell clones isolated, SV-2 cells showed a typical endothelial cell morphology. This cell line acquired a prolonged life span, but entered crisis at around 100 generations. On the other hand, SV-3T acquired an infinite life span and was morphologically transformed, although losing the ability to produce the factor VIII-related antigen which is specific for endothelial cells. ${ }^{15}$ ) Since SV-3T cells appeared after the crisis of SV-3 cells, it seems that several mutations occurred and that these mutations caused the acquisition of the infinite life span. After the morphological change, the chromosome number of SV-3 increased, and heteroploid cells became dominant after 222 generations. Furthermore, G-banding analyses indicated that multiple chromosomal aberration had occurred (data not shown). Therefore, it is quite possible that chromosomal aberration caused the morphological transformation. Many studies have shown that chromosome changes are critical for the immortalization and malignancy of human cancer. ${ }^{8,12)}$

As shown in Fig. 7, the chromosome number of the SV-2 and SV-3 cells showed certain distributions. This result suggests the possibility that SV-2 and SV-3 were not pure cell populations even after the single-colony isolation. Furthermore, the change in chromosome number at 100 generations with $\mathrm{SV}-3$ suggests the possibility that the genome con- 
struction of SV-3 and also of SV-3T may be changing. Since we have not yet checked the chromosome number of SV-3T, an extensive study will be necessary in this respect for the application of these cells.

Besides the infinite life span, SV-3T still retained some of the characteristics of normal endothelial cells such as its ability to produce tPA and PAI-1. This result suggests the possibility of getting cell lines which have both an infinite life span and the most interesting characteristics of the original differentiated cells, although it is still relatively difficult to obtain such cell lines with a human primary culture. In this regard, it is noteworthy that Yamashita and Mitsui have reported a spontaneous human endothelial cell clone with an infinite life span which retained several endothelial cell-specific characteristics. ${ }^{22)}$

A human endothelial cell line with a prolonged or infinite life span and the characteristics of differentiated cells is easy to handle and culture on a large scale. Furthermore, this kind of cell line will be very useful for basic research into endothelial cells. The further characterization of SV-3T is under investigation to apply these cells for the production of useful biological substances.

Acknowledgments. The authors are grateful to Ms. Takako Yamagishi, Ms. Chikage Nakajima and $\mathrm{Mr}$. Takaaki Tanase for their technical assistance. The authors are also indebted to Professor Kaoru Suzumori of Nagoya City University for isolating the endothelial cells. This work was supported in part by a Grant-in-Aid for Scientific Research (No. 03650784) from the Ministry of Education, Science and Culture of Japan.

\section{References}

1) Experimental Medicine (in Japanese), Vol. 6, No. 13 (1988).

2) Current Communications in Molecular Biology,
"Angiogenesis," ed. by D. B. Rifkin and M. Klagsbrun, Cold Spring Harbor Laboratory Press, NY, 1988.

3) E. A. Jaffe, P. L. Nachman, C. G. Becker and C. R. Minick, J. Clinic. Invest., 52, 2745 (1973).

4) T. Macing, J. Cerundolo, S. Hsley, P. R. Kelley and R. Forand, Proc. Natl. Acad. Sci. U.S.A., 76, 5674 (1979).

5) H. Hoshi and W. L. Mckeehan, Proc. Natl. Acad. Sci. U.S.A., 81, 6413 (1984).

6) R. Montesano, J. D. Vassalli, A. Baird, R. Guillemin and L. Orci, Proc. Natl. Acad. Sci. U.S.A., 83, 7297 (1986).

7) D. Neufeld, S. Ripley, A. Henderson and H. L. Ozer, Mol. Cell. Biol, 7, 2794 (1987).

8) T. Hunter, Cell, 64, 249 (1991).

9) P. Jat and P. A. Sharp, Mol. Cell. Biol., 9, 1672 (1989).

10) P. Tegtmeyer, in "DNA Tumor Viruses," ed. by J. Tooze, Cold Spring Harbor Laboratory Press, NY, 1981, pp. 297-338.

11) D. I. H. Linzer, W. Matzman and A. J. Levine, Virol., 98, 308 (1979).

12) S. Linder and H. Marshall, Exp. Cell Res., 191, 1 (1990).

13) S. Abcouwer, P. S. Robinson, C. F. Goochee and M. T. Crow, Bio/Technol., 7, 939 (1989).

14) Y. Gluzman, R. J. Frisque and J. Sambrook, Cold Spring Harbo Symp. Quant. Biol., 44, 293 (1980).

15) E. A. Jaffe, L. W. Hoyer and R. L. Nachman, J. Clinic. Invest., 52, 2757 (1973).

16) T. Maniatis, E. F. Fritsch, J. Sambrook, in "Molecular Cloning, A Laboratory Manual," Cold Spring Harbor Laboratory Press, NY, 1982.

17) F. A. Bignor, C. Panarello and G. Gimelli, Human Genet., 63, 63 (1983).

18) M. Kamihira, I. Kawakubo, M. Taniguchi, S. Iijima and T. Kobayashi, J. Chem. Eng. Jpn., 21, 357 (1988).

19) R. L. Heimark, D. R. Twardzik and S. M. Schuwartz, Science, 233, 1078 (1978).

20) M. Klagsbrum, J. Sasse, R. Sullivan and J. A. Smith, Proc. Natl. Acad. Sci. U.S.A., 83, 2448 (1986).

21) S. Thornton, S. N. Mueller and E. M. Levine, Science, 222, 623 (1983).

22) $Y$. Yamashita and $Y$. Mitsui, in Experimental Medicine (in Japanese), Vol. 6, No. 14 (1988), pp. 1333. 